\title{
THE CASE STUDY OF BOTTLENECKS IDENTIFICATION FOR PRACTICAL IMPLEMENTATION TO THE THEORY OF CONSTRAINTS
}

doi:10.2478/mape-2018-0051

Date of submission of the article to the Editor: 03/2018

Date of acceptance of the article by the Editor: 07/2018
MAPE 2018, volume 1, issue 1, pp. 399-405

\author{
Prof. Wieslaw Urban \\ Patrycja Rogowska \\ Bialystok University of Technology, Poland
}

\begin{abstract}
According to the Theory of Constraints by Goldratt system bottlenecks are key to improving productivity and profitability of the entire production system. An important issue in the practical application of this theory is to identify bottlenecks in the system. The aim of this paper is to develop practical steps to identify bottlenecks in the production system characterised by a homogeneous flow. The paper includes a case study which shows six steps that allowing to specify not only the first bottleneck of the system but to develop a comprehensive plan for removing bottlenecks.
\end{abstract}

Keywords: Theory of Constraints, bottlenecks identification, production flow

\section{INTRODUCTION}

The search for bottlenecks and focusing on relieving them is a leitmotif throughout the Theory of Constraints by Goldratt (1990). Bottlenecks limit the capacity and throughput of the production system, resulting in, among others, stagnant production, local accumulation of stocks, and above all reduced productivity of the system as a whole. The identification of and clearing bottlenecks are the basis for improvement of production and economic results achieved by a company. But on the other hand, acting according to the Theory of Constraints involves the need to solve a number of practical problems. One of them is the identification of bottlenecks in the production system.

The purpose of this paper is to determine the procedure to be followed to identify a bottleneck in the production system, as well as subsequent bottlenecks that should be subjected to improvements in line with the approach proposed by the Theory of Constraints by Goldratt. The research was conducted using a case study. The object of the study is the system of production of building materials characterised by a homogeneous flow, i.e. variability of product range that practically does not affect the characteristics of the product flow through the manufacturing system. The identified steps to be used to define bottlenecks are also important in utilitarian terms because there are few studies showing the practical applications of the Theory of Constraints in relation to different configurations and characteristics of the production system.

\section{THEORY OF CONSTRAINTS AS THE BASIS OF MANUFACTURING SYSTEM DEVELOPMENT}

The guarantee of success of the organisation is the flexible adaptation of production to changing market and customer requirements (Dulin et al., 2016). To enable a company to quickly and fully meet the needs of potential clients it must have high efficiency with maximum production flexibility (Jagodzinski, 2016). But it is not so easy, because variability of 
production, scarcity of resources such as technology or personnel may constitute a bottleneck, which limits the capacity of the production system (Lei and Li, 2017).

In the production process there are two types of bottlenecks differing in the level of their utilisation. The first type is exceeding the level of utilisation of performance limits of the constraint. An area of this type reduces the flow of goods and materials generating performance limits in the whole production system. While the second type is $100 \%$ utilisation of the resource capacity. Such a situation poses an extreme threat to the efficiency of production processes. This area has the highest degree of exploitation (high risk of failure) as well as affects the duration of the whole production process (Kolinski and Tomkowiak, 2010). To efficiently identify, manage and eliminate production bottlenecks, you can use the methodology of the Theory of Constraints (ToC), whose founder is an Israeli physicist Dr. Eliyahu M. Goldratt (Saniuk and Saniuk, 2010). This tool is widely used in a production environment, i.e. production planning, enterprise resource management, risk management, project management, marketing and accounting (Szatkowski, 2014). Its basic premise is that any process or system has one constraint that determines its performance. As mentioned earlier, this concept gives scope for identification of constraints and their appropriate management. The first step is to exploit the maximum production capacity of a bottleneck. If the bottleneck work schedule continues to be a barrier to the company's production capacity, the next step is to take action aimed at the reduction or complete elimination of this constraint (Kedzierski, 2016). Keep in mind that attempts at eliminating the constraint in one place lead to the identification of further constraints or the occurrence of new bottlenecks. Therefore it is important to constantly improve the manufacturing process of products (Kasemset and Kachitvichyanukul, 2010).

According to Goldratt (1990) a constraint is everything that prevents the organisation from achieving its goal. The authors classify constraints as follows: market constraint, capacity constraint, political constraint, raw material constraint, logistics constraint, behavioral constraint and administrative constraint (Okutmus et al., 2015). Among them constraints in the production flow capacity are typical production bottlenecks. Constrains identification is a fundamental issue for ToC when it comes to its practical implementation in a real production system. Alsmadi et al. (2014) suggest starting from financial record analysis whilst aiming at identifying constraints, they are recognised when the operation of the system is tied to spent costs. Another approach to look for constraints is by simulating a system model (Golmohammadi, 2015; Costas et al., 2015). This approach refers for to capacity in bottlenecks and exploits a multiproduct production/logistic system, the point is how to determine the most favourable structure of the manufactured assortment. But also, an interesting issue is how to identify constraints/bottlenecks in a homogeneous production flow.

\section{INVESTIGATED MANUFACTURING SYSTEM}

The studies company is a manufacturer of building materials. The main raw materials used for production of silicate blocks are lime, sand and water. The key machinery of the company includes silos, mixers, reactors, autoclaves and moulding presses. The plant produces 17 kinds of products. The production process of silicate blocks is carried out in five major steps: 1. Storage and mixing of raw materials - raw materials are stored in silos which are then subjected to stirring in an appropriate proportion. 2. Transformation of the mixture in lime hydrate - adding water to the mixture, which is then placed in reactors where slaking occurs. 3. Formation - presses form silicate blocks at a pressure. 4. Hardening - placing semi-finished products in an autoclave at $200^{\circ} \mathrm{C}$, where recrystallisation of the mixture occurs. 5. Quality control and packing - subjecting blocks to quality control followed by stacking on pallets. The company operates in three shifts, six days a week. The flow of materials and semi-finished products takes place between the various processes in an automatic or semi-automatic manner. 
Due to the uneven use of production resources, the company decided to analyse its production capacity. The company is interested in improving the productivity of the system as a whole. Below are the analytical research steps carried out in the company to build an appropriate information framework that will clearly identify a bottleneck and subsequent bottlenecks, including the directions of work on improvement of the system.

\section{BOTTLENECKS IDENTIFICATION STEPS}

\subsection{Identification of the flow sequence (STEP \#1)}

The first step taken in order to identify a bottleneck is the observation of the company's production system and the actual measurement of cycle times in every production process. This action will allow to order processes occurring consecutively, which are not always in line with the business records. Process observation was made for one type of product to be manufactured. The analysis was extended to include the necessary information, i.e. the quantity of available production resources for parallel processes and the number of pieces of product in one process cycle, which indicates how many product units leave the process. Table 1 presents the results of the observation of the production system.

Table 1

Identification of the sequence of the production system flow and the number of parallel processes

\begin{tabular}{|l|c|c|c|}
\hline \multicolumn{1}{|c|}{ Process/operation } & $\begin{array}{c}\text { Process/ } \\
\text { operation cycle } \\
\text { time } \\
\text { [sec] }\end{array}$ & $\begin{array}{c}\text { Number of } \\
\text { available } \\
\text { productive } \\
\text { resources }\end{array}$ & $\begin{array}{c}\text { Number of } \\
\text { pieces of } \\
\text { product in one } \\
\text { cycle }\end{array}$ \\
\hline Formation & 9 & 3 & 5 \\
\hline Placing semi-finished products on hardening trolleys & 37 & 3 & 20 \\
\hline Internal transport of hardening trolleys & 257 & 1 & 480 \\
\hline Hardening & 25403 & 6 & 4320 \\
\hline Unstacking & 382 & 3 & 4320 \\
\hline Palletising & 130 & 1 & 240 \\
\hline Securing the product & 140 & 1 & 160 \\
\hline Transportation to the warehouse & 73 & 1 & 320 \\
\hline
\end{tabular}

In the following studies a "production unit" is composed of 5 pieces of products manufactured in a single cycle of the moulding machine.

\subsection{Investigation of unit processes (STEP \#2)}

The intent of this step is to examine what time is needed for each production unit to pass through each of the previously identified processes based on the quantity of available production resources. This analysis will allow to determine which process or production step is the most time-consuming. Fig. 1 shows the results of this stage.

Analysing Fig. 1 it can be concluded that the most time-consuming process is product hardening. But the base times do not take into account unproductive losses occurring in the industry. Therefore, the next steps to identify a bottleneck should take account of all types of waste that occur in the examined production process. 


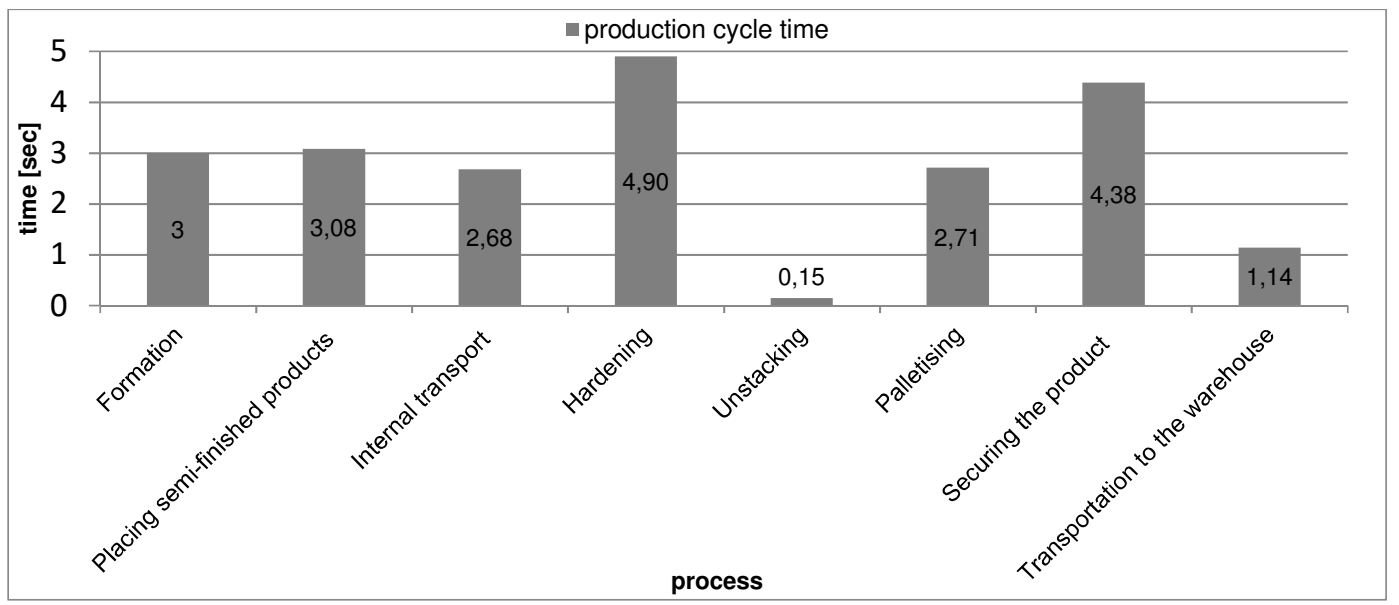

Fig. 1. Process cycle times

4.3. Investigation of process cycle times with reference to production losses due to product quality (STEP \#3)

As already mentioned, important factors influencing the productivity of processes are production losses. As a result of observation of the analysed manufacturing process, the first type of waste concerning product quality was identified. This issue affects the process of moulding products. Approx. 15\% of products on each moulding press are damaged. The factor causing the gaps is incorrect humidity of the raw material mixture. Taking into account this factor, the time needed for a production unit to undergo each process is shown in Fig. 2.

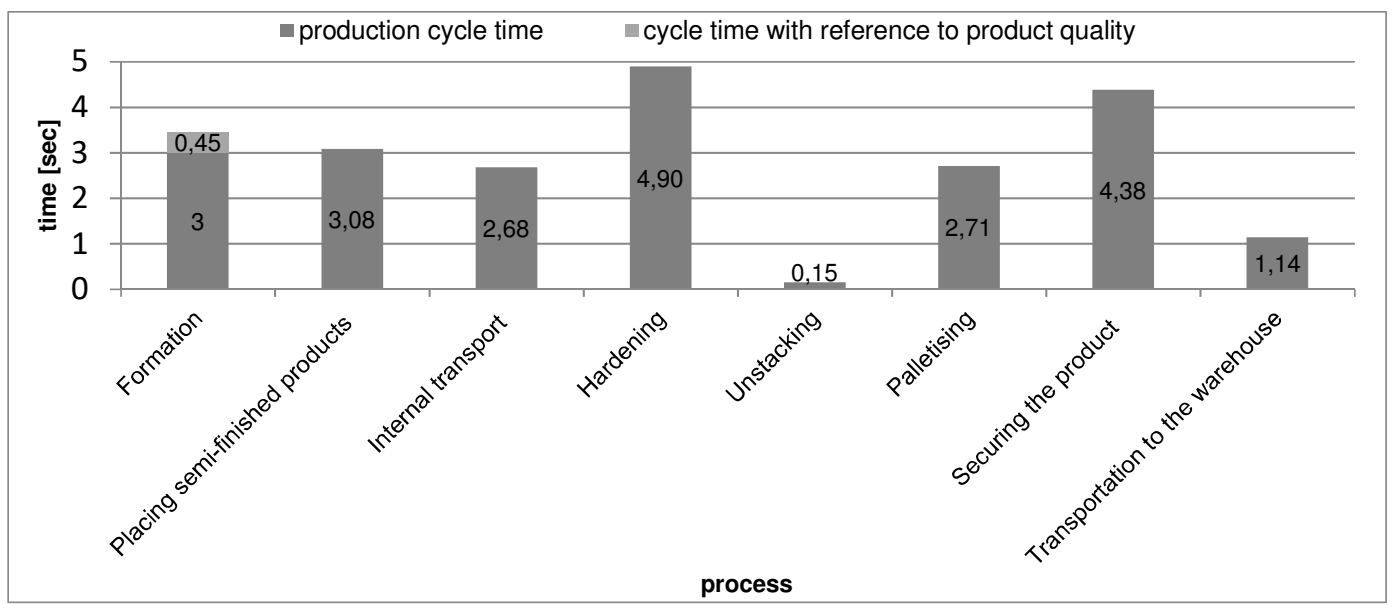

Fig. 2. Process cycle times with reference to product quality

As a result of taking account of losses which occur during the moulding process, the time to produce a unit product for 3 presses increased by 0.45 seconds. The total moulding process time for the adopted production unit is 3.45 seconds. Other process times remain unchanged.

\subsection{Investigation of process cycle times with reference to machine changeover time (STEP \#4)}

Another unproductive loss affecting the identification of a bottleneck in the production system is machine changeover time. The analysis of the investigated manufacturing process showed that machine changeover takes place on moulding presses (moulding process). 


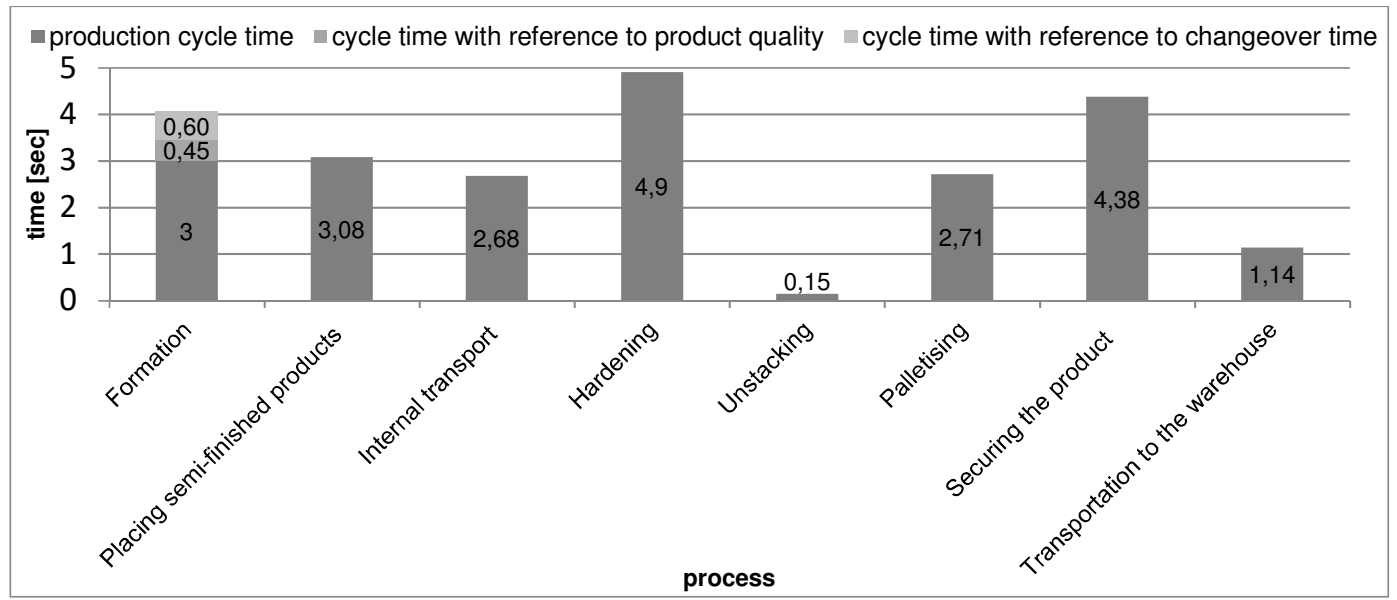

Fig. 3. Process cycle times with reference to changeover time

The changeover time factor should be considered as Step 4 to enable the identification of production system constraints.

When analysing enterprise data it was found that there are about 9 product moulding press changeovers a month. The changeover time is 6 hours. An average batch manufactured by the company is 750 hardening trolleys. The results of analysis are shown in Fig. 3.

Based on the aforementioned assumptions, changeover time per production unit is 0.6 seconds. So the total moulding process time for the adopted production unit is 4.05 seconds. Other process times remain unchanged.

\subsection{Organisation of working time for individual resources (STEP \#5)}

Another important step is to examine the extent of utilisation of the operation time for each resource. The company on average manufactures approx. 121 hardening trolleys containing a total of 5,184 production units per one production shift. If you know the duration of each stage of the production process per production unit taking into account all the factors affecting its duration, you can easily calculate the time of unused availability of all resources. The results are shown in Fig. 4.

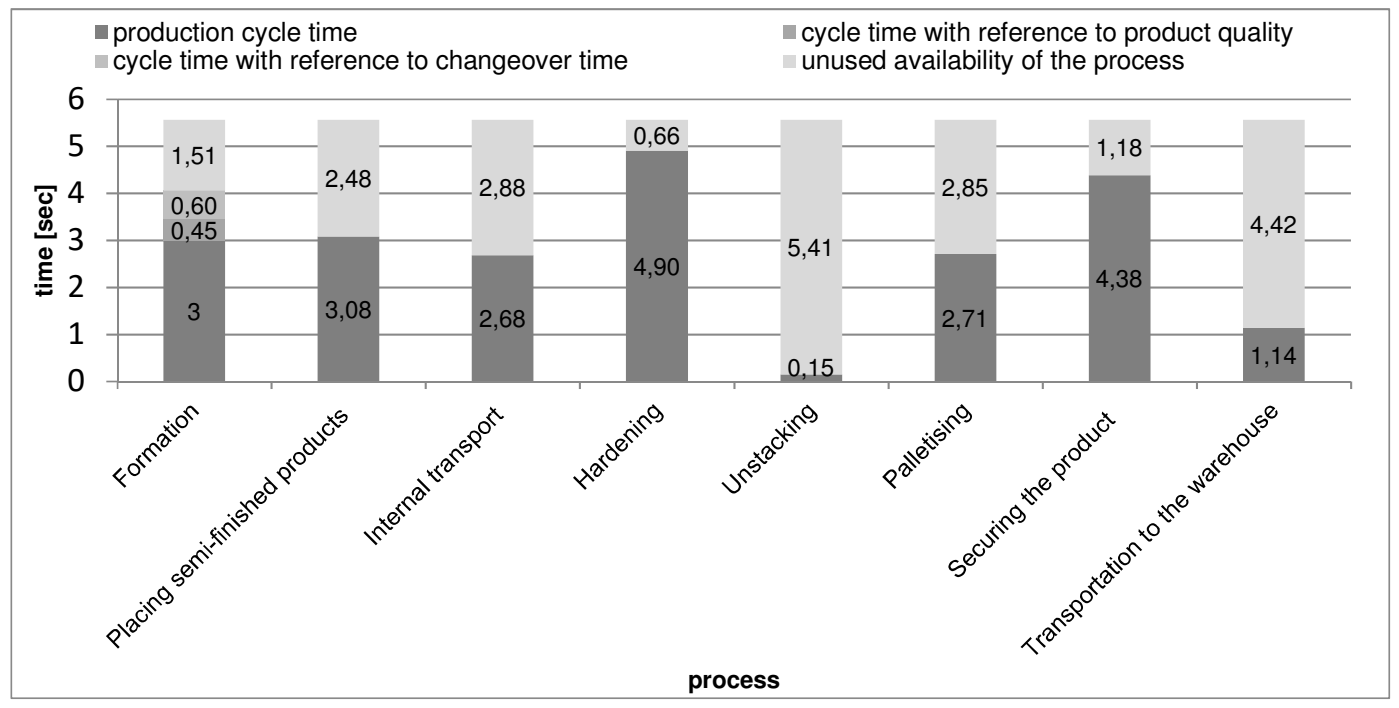

Fig. 4. Process cycle times with regard to unused availability 
The average resource availability per production unit is 5.56 seconds. Analysing the above data it is clear that the availability of resources is not fully utilised. The most effectively utilised process is product hardening.

\subsection{Analysis of the structure of process cycle times (STEP \#6)}

On the basis of the information in Step 5 it can be concluded which resources/processes generate bottlenecks in the production system. It also shows the resulting type of cycle time components. We identified 3 key bottlenecks in the production system in question, i.e. hardening, product protection and moulding. The ToC logic tells to sequentially relieve bottlenecks one after another, each time with a view to improving system capacity and increase throughput. Table 2 shows a sequence of tasks that should be introduced to improve the production system studied. When determining the degree of utilisation of the processes, full scalability of the production capacity of processes was assumed, which in practice does not always coincide with actual possibilities.

Table 2

Further improvement of the production system bottlenecks

\begin{tabular}{|l|l|c|c|}
\hline $\begin{array}{c}\text { Item } \\
\text { No. }\end{array}$ & \multicolumn{1}{|c|}{ Improvement / Process } & $\begin{array}{c}\text { Cycle time of the system after } \\
\text { relieving a bottleneck }\end{array}$ & $\begin{array}{c}\text { Degree of } \\
\text { utilisation of } \\
\text { processes }\end{array}$ \\
\hline 1. & $\begin{array}{l}\text { Maximum utilisation of the availability of } \\
\text { hardening }\end{array}$ & 4.90 & $56.2 \%$ \\
\hline 2. & $\begin{array}{l}\text { Increasing hardening production capacity } \\
\text { by supplying resources }\end{array}$ & 4.38 & $62.9 \%$ \\
\hline 3. & $\begin{array}{l}\text { Increasing securing production capacity by } \\
\text { adding resources }\end{array}$ & 4.05 & $68 \%$ \\
\hline 4. & $\begin{array}{l}\text { Improving changeovers and elimination of } \\
\text { defects in moulding }\end{array}$ & 3.08 & $89.4 \%$ \\
\hline
\end{tabular}

However, steps towards the exploitation of bottlenecks should be preceded by steps to ensure maximum utilisation of the production capacity of the hardening process. These actions should be adapted so that the system worked in a rhythm equal the production cycle of the process (Improvement 1 in Table 2 above). In the next step, the bottleneck which is product hardening should be cleared through the supply of resources. After the removal of this constraint, product safety should be taken into account. The data in Table 1 indicate that the process is performed by a single worker. Therefore, in order to relieve the bottleneck, the number of employees dealing with securing finished products should be increased. The last process important due to its time-consuming nature is moulding. To increase throughput, losses generated in this process should be eliminated and the moulding press changeovers should be improved.

\section{CONCLUSION}

The identification of bottlenecks and their elimination have a significant impact on the efficiency of the production system of the company. The first course of action was to examine how the analysed production system actually works and the cycle times of the examined processes. Another important factor that has a significant impact on the production system is to identify all types of waste generated in the process. In the studied company, 3 types of waste were identified, i.e. due to manufacturing defects, machine changeover time and improper organisation of shift work resulting in underutilisation of the available processes. These are typical losses so each next step (2 to 5 ) should be devoted to each of them individually. This results in a graphical presentation of the time structure of individual processes, which allows you to draw conclusions as to existing bottlenecks and the sequence of actions to be taken to eliminate them.

The proposed production process bottleneck identification logic allows to indicate limitations of the system and gives guidelines on how to improve the direction of the production system. 


\section{ACKNOWLEDGEMENTS}

Research have been carried out in the framework of work S/WZ/1/2015 and financed by Ministry of Science and Higher Education from the funds for science.

\section{REFERENCES}

Alsmadi, M., Almani, A. and Khan, Z. (2014). Implementing an integrated ABC and TOC approach to enhance decision making in a Lean context: a case study. International Journal of Quality \& Reliability Management, 31(8), pp. 906-920.

Costas, J., Ponte, B., de la Fuente, D., Pino, R. and Puche, J. (2015). Applying Goldratt's Theory of Constraints to reduce the Bullwhip Effect through agent-based modeling. Expert Systems with Applications, 42, pp. 2049-2060.

Dulina, L., Mleczko, J. and Mičieta, B. (2013). Identification of Bottlenecks in the Unit Make to Order Production. Applied Computer Science, 9(2), pp. 43-56.

Goldratt, E.M. (1990). What is This Thing Called Theory of Constraints and How Should it be Implemented? New York: North River Press.

Golmohammadi, D. (2015). A study of scheduling under the theory of constraints. International Journal of Production Economics, 165, pp. 38-50.

Jagodziński, J. and Ostrowski, D. (2016). The production process optimization based on the principle of continuous improvement on the selected example. Zarządzanie, 24(2), pp. 201-214, (in: Polish).

Kasemset, C. and Kachitvichyanukul, V. (2010). Bi-level multi-objective mathematical model for job-shop scheduling: the application of Theory of Constraints. International Journal of Production Research, 48(20), pp. 6137-6154.

Kędzierski, P. (2016). Theory of Constraints in production planning. Logistyka Produkcji, 1(21), pp. 4345, (in: Polish).

Koliński, A. and Tomkowiak, A. (2010). Using the analysis of bottlenecks in production management. Gospodarka Materiałowa i Logistyka, 9, pp. 16-21, (in: Polish).

Lei, Q. and Li, T. (2017). Identification Approach for Bottleneck Clusters in a Job Shop on Theory of Constraints and Sensitivity Analysis. Journal of Engineering Manufacturing, 231(6), pp. 10911101.

Okutmus, A., Kahveci, A. and Kartašova, J. (2015). Using theory of constraints for reaching optimal product mix: An application in the furniture sector. Intellectual Economics, 9, pp. 138-149.

Saniuk, A. and Saniuk, S. (2010). Theory of constraints applied to resources management in micro and small-sized enterprises. Ekonomiczne Problemy Usług, 50(585), pp. 355-363, (in: Polish).

Szatkowski, K. (2014). Modern production management. Warsaw: Wydawnictwo Naukowe PWN, (in: Polish). 